\title{
Perceptions of Critical Care Family Needs in the Kingdom of Saudi Arabia
}

\author{
Al Faydhi, A. ${ }^{1,}$ Mohidin, S. ${ }^{2,}$ Nuzhat, S. ${ }^{3}$ Shalaby, S. ${ }^{4}$ Al-Tabsh, L ${ }^{5,}$ \\ \&Aleidarous, $\mathrm{S}$. \\ ${ }^{I}$ Medical Intensive Care Unit,King Abdulaziz University Hospital Jeddah Kingdom of Saudi Arabia \\ ${ }^{2}$ Nursing Clinical Practice \& Research Unit, King Abdulaziz University Hospital Jeddah Kingdom of Saudi \\ Arabia \\ ${ }^{3}$ Surgical Intensive Care Unit,King Abdulaziz University Hospital Jeddah Kingdom of Saudi Arabia \\ ${ }^{4}$ Emergency Unit,King Abdulaziz University Hospital Jeddah Kingdom of Saudi Arabia \\ ${ }^{5}$ Nursing Administration, King Abdulaziz University Hospital Jeddah Kingdom of Saudi Arabia \\ ${ }^{6}$ Quality Department, King Abdulaziz University Hospital Jeddah Kingdom of Saudi Arabia
}

\begin{abstract}
:
Introduction: Gaining an increased understanding of family members' satisfaction of critical care might lead to improved family care. This study explored the self-perceived needs of health care workers (HCWs) and the family members of intensive care unit (ICU) patients.

Method: A non-experimental comparative descriptive cross-sectional study was conducted between April 2013 and September 2013 at the surgical and medical ICU of King Abdulaziz University Hospital using the Critical Care Family Needs Inventory (CCFNI). The relatives or caregivers of ICU patients and HCWs were invited to fill in the survey instrument.

Results: A total of 132 participants of 186 filled in the questionnaires, representing a response rate of $71 \%$. Health care workers comprised 59.8\% of the sample $(n=79)$.Both HCWs and family members identified assurance as their first area of need, with a mean difference of 0.46 higher for family members. Health care workers ranked comfort as second, information as third, followed by support, and finally proximity needs. Conversely,family members felt they wanted information and proximity, followed by comfort and support. Health care workers perceived that family members would like to know the expected outcome as the most important need; however, family members' selected item was to have questions answered honestly, which was categorized as second in rank by the HCWs. Both HCWs and family members selected the item "visiting at any time" as the least important need. Family members' needs, such as to have a place to be alone, to have friends nearby, to talk about negative feelings and to have someone to help financially, was not placed as a priority for them; whereas, HCWs placed seeing the patient frequently as one of the family's least important needs.

Conclusion:family members and HCWs place a high priority on assurance. However, the discrepancies in the perceptions of family members and HCWs suggest that a shift in the practice and perceptions of the clinical staff may help family members to better cope with the critical illness of their relative.
\end{abstract}

\section{Introduction}

The president of the World Organization of Family Doctors (WONCA) in the Middle East wants the Saudi Ministry of Health to propose legislation that will support the establishment of networks of patient-centered care units across the Kingdom to further improve the medical care system in Saudi Arabia (Saudi Gazette, 2013).Family-centered care is a global philosophical approach in which families are both recipients of care aimed at optimizing their well-being, as well as active participants in care provided to the patient. Family participation in care is only one component of family-centered care. Intensive Care Units (ICUs) are places where the critically ill receive technologically sophisticated care and where the primary goal of therapy is to help patients recover from acute threats to their health. An intensive care unit is a specialized area of the hospital where expert care of critically ill patients can be delivered efficiently. It is a specialty that involves the management of patients with life-threatening, frequently complex medical and surgical illnesses. Due to the severity of illnesses, most ICUs limit visiting hours only to one hour, twice daily. On the other hand, family involvement in nursing care hasbeen reported to be beneficial for patients and nurses, as family members provide important support and resources for a critically ill person; however, family members also have their own needs when someone they care for is seriously ill (Burr, 1998, 2001). According to L"of et al. (2006) gaining the trust and confidence of family members is of great significance in reducing and preventing worry, inner tension and confusion among critically ill people. Family members of critically ill people often experience a sudden and difficult change in their everyday lives when someone they love and care for is stricken by an acute or severe illness or trauma. These changes can be affected by previous experiences, values, the circumstances surrounding the event and their uncertainty about the 
outcome (Curry, 1995).Visiting a critically ill close relative in the alien, high-tech ICU is often an unfamiliar experience that might generate fear and uncertainty (McGrath, 2008). Interventions are carried out around the clock by the ICU staff that care for critically ill people and monitor changes in their condition (Stichler, 2001). It is the alien technical environment itself that can be stressful. The ill person can appear strange when surrounded by tubes and wires, and may be difficult to recognize because of general swelling or traumatic injury (Engstr"om and S" oderberg, 2004). The most common sources of stress for family members include uncertainty about the prognosis and outcome, and the risk of permanent disability (Holden et al., 2002).

Holden et al. (2002) have shown that family members appreciate timely and honest information. Family members want to receive information about the ill person's treatment, interventions, medical condition, changes in condition, what was done and what is planned for them. Receiving information is important, even if it is upsetting. By feeling the staffs' empathy and receiving clear and intelligible information, family members felt that their emotional needs were met (Brown et al., 2000). Several studies (Curry, 1995; Robb, 1998; De Jong and Beatty, 2000) indicate that it is important for the family to see their ill relatives often and to be allowed to visit whenever they want. In some studies (Coulter, 1989; Leske, 1991; Bijttebier et al., 2000) the authors used an instrument called Critical Care Family Needs Inventory (CCFNI). The CCFNI was developed by Molter (1979) to identify and rank the needs of family members of critically ill people.

Many studies have focused on the needs of family members of critically ill people, but studies investigating their satisfaction with the care are lacking. Gaining an increased understanding of family members' satisfaction of critical care might lead to improved family care. One way of measuring family satisfaction is using the Critical Care Family Satisfaction Survey (CCFSS). The CCFSS is an instrument used to measure family members' satisfaction of critical care, which includes both quantitative and qualitative data. The aim of this pilot study was to describe family members' satisfaction with the care, based on their need for assurance, information, proximity, support and comfort, which are all included in the CCFSS.

This study explored the self-perceived needs of health care workers (HCWs) and the family members of patients who have been admitted to an ICU, using the critical care family needs. The specific aim of the current study was

- To identify the self-perceived needs of family members who have relatives in ICU in five areas: support, comfort, information, proximity and assurance as the priority in the family member

- To explore the similarities and different needs identified by family members and HCWs

- To identify the rank order of the five most important needs as perceived by family members as compared to HCWs

- To identify the rank order of the five least important needs as perceived by family members as compared to HCWs

\section{Methodology}

This was a non-experimental comparative descriptive cross-sectional study that was conducted between April 2013 and September 2013 at the surgical and medical ICU of King Abdulaziz University Hospital, a teaching hospital in Jeddah, Saudi Arabia. A convenience sample of both relatives and HCWs was selected. The participants included either family members or caregivers of patients admitted to the Critical Care Unit of King Abdulaziz University Hospital during the study period. The HCWs included nurses and physicians caring for the patients during the data collection period.The Critical Care Family Needs inventory (CCFNI) is a 46-item, 4-point Likert-type questionnaire with 45 specific items and one general item for respondents to list a need of their choosing that is not included on the questionnaire. It measures the needs of family members following the critical illness of a family member. Additional demographic data for HCWs was integrated, such as job title and years of experience in the ICU.

Permission to conduct this study was obtained from the Nursing Department of the hospital and the Ethics Research Committee at King Abdulaziz University. All the ward managers of the ward were informed, in order to obtain cooperation and support. The family's consent was obtained prior to data collection. The HCWs (nurses and doctors) were given a brief explanation regarding the purpose of the study. The study wasconducted anonymously and on a voluntary basis. Confidentiality was assured.

\section{Statistical analysis}

The data were analyzed with descriptive and inferential statistics using SPSS for Windows, Release 18.0. Pre-analysis data screening was conducted prior to statistical analysis to examine coding errors, outliers and data skewness, to determine if any data cleaning procedures were needed. Descriptive statistics, including frequencies, percentages, means and standard deviations, were performed and reported on the health care workers (HCWs) and on patient's family members' (FMs) demographic variables, HCWs' patient/family-centered care beliefs and FMs perception of patient/family-centered care according to appropriate level of measurement. 


\section{Results}

Onehundred eighty-six participants were given the questionnaire; however, only 132 questionnaires were fully completed $(71 \%)$. Health care workers comprised $59.8 \%$ of the sample $(n=79)$.The means, standard deviations and difference of means between the HCWs and families for the 44 questions in the CCFNI are shown in Table 1. The comparison of the ranked means is important, as it demonstrates the compatibility of ranking in terms of importance across both groups.

\section{Research objective 1:}

Data were analyzed to measure five areas: support, comfort, information, proximity and assurance as the priority between the groups.Both groups identified assurance as their first area of need, with a mean difference of 0.46 higher for family members.Health care workers ranked comfort as second, information as third, followed by support, and finally proximity needs.Conversely,family members felt they wanted information and proximity, followed by comfort and support.

\section{Research objective 2:}

This aimed to identify the rank order of the five most important needs as perceived by family members as compared to HCWs. In meeting the second objective of the study, the results are shown in Table 2.Health care workers perceived that family members would like to know the expected outcome as the most important need; however, family members' selected item was to have questions answered honestly, which was categorized as second in rank by the HCWs.

\section{Research objective 3:}

The analysis also demonstrated differences in the five least important needs identified by HCWs and family members. Both HCWs and family members selected the item "visiting at any time" as the least important need. Family members' needs, such as to have a place to be alone, to have friends nearby, to talk about negative feelings and to have someone to help financially, was not placed as a priority for them; whereas, HCWs placed seeing the patient frequently as one of the family's least important needs.

\section{Research objectives 4:}

In addition, this study considered the similarities perceived by both HCWs and family member groups in the list of the family needs (Table 4).

\section{Discussion}

Our analysis demonstrated that both family members and HCWs identified assurance as the first area of need. Nevertheless, family members and HCWs differed in their perception of other areas of need, including support, comfort, information, and proximity. While a similar study has been conducted across eight adult mixed medical-surgical ICUs in Saudi Arabia (Al-Mutair et al., 2013), this study is the first to examine the perceptions of relatives and HCWs regarding family members' needs in a critical setting at King Abdulaziz University Hospital.

In the current study, family members rankedinformation and proximity, followed by comfort and support as important areas of need, while HCWs appeared to place more importance on emotional needs. This finding is consistent with that of Al-Mutair et al. (2013) who identified the needs of families of adult ICU patients in Saudi Arabia as perceived by family members and healthcare providers. In their report, they found that the assurance and information subscales were ranked as the first and second most important dimensions on the CCFNI as perceived by family members. On the other hand, they found that health care providers also ranked the assurance and information subscales as the first and second most important dimensions. Contrary to our report, findings from other studies that investigated the needs of family members of ICU patients showed that family members ranked proximity to the patient as the most important need (Verhaeghe et al., 2005; Hinkle and Fitzpatrick, 2011; Khalaila, 2013).

While HCWs in the current study perceived that family members would like to know the expected outcome as the most important need, family members reported that it was important to have their questions answered honestly. In another study conducted abroad, Pinkert et al. (2013) reported that family members assessed the importance of needs considerably differently than nurses, with nurses overestimating the need for emotional support. Furthermore, Pinkert et al. (2013) reported that family members wanted to be involved in the direct care of their patients and wished to participate in decision-making processes. It is plausible that these differences lie primarily in the need for family members to put their patients in trusted care, and they want to be informed honestly about their patients' disease and treatment (Eberl and Schnepp, 2008). In addition, previous reports have shown that the need for information is of prime importance to family members (Jefford et al., 2005; Tunin et al., 2010). Such discrepancies in the assessment of needs are to be expected, as previous findings suggest 
that HCWs make special efforts to meet needs for which they believe are very important to patients' relatives (Pinkert et al., 2013). Unfortunately, their perceptions in most cases are usually incorrect.

Similar to the most important areas of need, HCWs and family members differed on their perceptions of the least important need, although they agreed that "visiting at any time"was not important. Given restricted visiting times, as is the norm in most ICUs in Saudi Arabia, this may explain why families expressed the need to be reassured by the ICU team. While HCWs placed seeing the patient frequently as one of the family's least important needs, family members reported needs, such as to have a place to be alone, to have friends nearby, to talk about negative feelings and to have someone to help financially as items of least priority. Conversely, in Khalaila's (2013) report, family members identified visiting time as a very important need. In another report, (Pinkert et al., 2013)family members reported "being consoled" (21\%), "being informed about the disease's impact on partnership and sexuality" (19\%), "being able to talk about sorrow" (19\%), "being able to talk about negative feelings" $(15 \%)$, and "talking about religious topics" $(6 \%)$ as the least important needs. On the other hand, nurses reported the need of "talking about religious topics" to be, to a great extent, the least important need. In ascending order, nurses reported "being informed about the disease's impact on partnership and sexuality", "having someone who is paying attention to their well-being", "being able to talk about negative feelings such as rage and guilt" and "having the opportunity to participate in decision-making processes dealing with the care of the patient"as less important needs.

\section{Conclusion}

Overall, family members and HCWs place a high priority on assurance. However, the discrepancies in the perceptions of family members and HCWs suggest that a shift in the practice and perceptions of the clinical staff may help family members to better cope with the critical illness of their relative. Future research should investigate family member's perceptions of needs that are met by HCWs at our institution. Furthermore, it may be necessary to investigate the steps undertaken by the clinical staff and administration as a whole to meet the needs of relatives of ICU patients.

\section{Key Messages:}

- Both family members and HCWs place a high priority on assurance.

- Healthcare Care workers need to appreciate the needs of family members of a patients being treated in a critical care area.

- Concern of the family in critical care unit patients is important to be taken into consideration to provide holistic care for the critically ill patients.

- Health care workers need to aware that the critical care family members could be as vulnerable as the critical illpatients, and experience varying responses to the loved one.

- Families need to be kept informed and actively involved in decision-making they could be integral to the healing process of a critically ill patient as they often offer a sense of security to the loved one.

- Family member just want to know the facts and truths and do not demand visiting frequently and at any time

\section{Abbreviations:}

1. CCFNI: Critical Care Family Needs Inventory

2. CCFSS: Critical Care Family Satisfaction Survey

3. HCW: Health Care Workers

4. FMs: Family Members

5. ICU: Intensive Care Unit

\section{Conflicts of interest:}

The authors declare that they have no competing interests.

\section{Authors' Contributions:}

"SM, AF and SNdesigned the study and participated in the sequence alignment and drafted the manuscript. SN carried out the study. SA participated in the design of the study and performed the statistical analysis. SS \&LT conceive of the study, and SM, SN and AFparticipated in its design and coordination and helped to draft the manuscript. All authors read and approved the final manuscript."

\section{Acknowledgment}

We would like to thank the hospital and nursing administration for giving us the opportunity to work on this project and all the staff who supported us directly and indirectly during this project. 
Table \& Figures

Table 1. Five Areas of the Critical Care Family Needs Inventory, Means and Standard Deviations for Families and Healthcare Workers

\begin{tabular}{|l|l|l|l|l|l|l|}
\hline & \multicolumn{4}{|l|}{ Healthcare workers } & \multicolumn{2}{|c|}{ Family Members } \\
\hline & Areas & Mean & SD & Areas & Mean & SD \\
\hline 1st & Assurance & 4.31 & 0.36 & Assurance & 4.77 & 0.31 \\
\hline 2nd & Comfort & 4.05 & 0.52 & Information & 4.54 & 0.40 \\
\hline 3rd & Information & 4.03 & 0.44 & Proximity & 4.46 & 0.41 \\
\hline 4th & Support & 3.59 & 0.45 & Comfort & 4.35 & 0.52 \\
\hline 5th & Proximity & 3.39 & 0.58 & Support & 4.29 & 0.44 \\
\hline
\end{tabular}

Table 2.Five Most Important Critical Care Family Needs Inventory Items as identified by Family Members and Nurses

\begin{tabular}{|c|c|c|}
\hline & Healthcare workers & Family Members \\
\hline 1 & A-To know the expected outcome & To have questions answered honestly \\
\hline 2 & A-To have questions answered honestly & $\begin{array}{l}\text { To be called at home about changes in the patient's } \\
\text { condition }\end{array}$ \\
\hline 3 & $\begin{array}{l}\text { S-To have explanations of the environment before going } \\
\text { into the critical care unit first time }\end{array}$ & $\begin{array}{l}\text { To be assured that the best care possible is being given to } \\
\text { patient }\end{array}$ \\
\hline 4 & I-To talk to the doctor every day & To be told the truth even if is distressing \\
\hline 5 & $\begin{array}{l}\text { A-To be assured that the best care possible is being } \\
\text { given to patient }\end{array}$ & To know the specific facts about the patient \\
\hline
\end{tabular}

Table 3.Five Least Important Critical Care Family Needs Inventory Items as Identified by Healthcare Workers and Family Members

\begin{tabular}{|l|l|l|}
\hline & Healthcare workers & Family Members \\
\hline 1 & To have friends nearby for support & To have place to be alone while in the hospital \\
\hline 2 & Talking about negative feeling such as rage and guilt & To have friends nearby for support \\
\hline 3 & To be alone at any time & Talking about negative feeling such as rage and guilt \\
\hline 4 & To see the patient frequently & To have someone help with financial problem \\
\hline 5 & To visit at any time & To visit at any time \\
\hline
\end{tabular}

Table 4.Similarities between Healthcare Workers and Family Members 'Perceived Needs

\begin{tabular}{|l|l|}
\hline \multicolumn{2}{|c|}{ Healthcare Workers and Family Members } \\
\hline 1 & A-to know the expected outcome \\
\hline 2 & A-to have questions answered honestly \\
\hline 3 & A-to be assured that the best care possible is being given to patient \\
\hline 4 & P-to be told about transfer plans while they are being made \\
\hline 5 & P-to receive information about the patient at least once a day \\
\hline
\end{tabular}

Table 5.Descriptive Statistics for Family Needs in Subscales (N=44 Items) ${ }^{1}$

\begin{tabular}{|c|c|c|c|c|}
\hline Group Statistics & $\begin{array}{l}\text { FMs } \\
(n=53)\end{array}$ & $\begin{array}{l}\mathrm{HCWs} \\
(\mathrm{n}=79)\end{array}$ & P-value & Mean Difference \\
\hline To visit at any time & $3.70(1.35)$ & $1.49(0.92)$ & $0.00 *$ & 2.20 \\
\hline To see the patient frequently & $4.60(0.60)$ & $2.63(1.46)$ & $0.00 *$ & 1.97 \\
\hline To be alone at any time & $4.32(0.87)$ & $2.72(1.15)$ & $0.00 *$ & 1.60 \\
\hline $\begin{array}{l}\text { To be called at home about changes in the patient's } \\
\text { condition }\end{array}$ & $4.83(0.38)$ & $3.59(1.04)$ & $0.00 *$ & 1.24 \\
\hline $\begin{array}{l}\text { To have another person with you when visiting the } \\
\text { critical care unit }\end{array}$ & $4.42(0.75)$ & $3.28(0.95)$ & $0.00 *$ & 1.14 \\
\hline Talking about negative feeling such as rage and guilt & $4.00(0.88)$ & $2.87(1.28)$ & $0.00 *$ & 1.13 \\
\hline To have visiting hours changed for specific conditions & $4.26(0.96)$ & $3.16(1.27)$ & 0.00 & 1.10 \\
\hline To have friends nearby for support & $4.13(0.68)$ & $3.09(1.15)$ & $0.00 *$ & 1.04 \\
\hline To talk about the possibility of patients death & $4.34(0.90)$ & $3.34(1.29)$ & $0.00 *$ & 1.00 \\
\hline To have place to be alone while in the hospital & $4.19(0.96)$ & $3.20(1.16)$ & $0.00 *$ & 0.99 \\
\hline To have the waiting room near the patient & $4.36(0.71)$ & $3.46(1.12)$ & $0.00 *$ & 0.90 \\
\hline To help with the patient physical care & $4.66(0.52)$ & $3.86(0.98)$ & $0.00 *$ & 0.80 \\
\hline To be told the truth even if is distressing & $4.79(0.45)$ & $4.03(0.73)$ & $0.00 *$ & 0.77 \\
\hline $\begin{array}{l}\text { To know about the types of staff members talking care } \\
\text { of the patient }\end{array}$ & $4.58(0.54)$ & $3.82(1.02)$ & $0.00 *$ & 0.76 \\
\hline To feel there is hope & $4.72(0.50)$ & $3.97(0.78)$ & $0.00 *$ & 0.74 \\
\hline To know the specific facts about the patient & $4.79(0.45)$ & $4.09(0.56)$ & $0.00 *$ & 0.70 \\
\hline To have a telephone near the waiting room & $4.32(0.89)$ & $3.65(1.08)$ & $0.00 *$ & 0.68 \\
\hline To be encouraged to express emotions & $4.38(0.77)$ & $3.75(0.76)$ & $0.00 *$ & 0.63 \\
\hline To be told about pastoral services & $4.40(0.60)$ & $3.78(0.78)$ & $0.00 *$ & 0.61 \\
\hline To have someone be concerned with your heath & $4.55(0.61)$ & $3.94(0.74)$ & $0.00 *$ & 0.61 \\
\hline To feel that the hospital personal care about the patient & $4.74(0.45)$ & $4.16(0.61)$ & $0.00 *$ & 0.57 \\
\hline
\end{tabular}




\begin{tabular}{|c|c|c|c|c|}
\hline $\begin{array}{l}\text { To have the specific person to call at the hospital when } \\
\text { unable to visit }\end{array}$ & $4.34(0.88)$ & $3.78(1.00)$ & 0.00 & 0.56 \\
\hline To know how the patient is being treated medically & $4.72(0.57)$ & $4.18(0.59)$ & $0.00^{*}$ & 0.54 \\
\hline $\begin{array}{l}\text { To know which type of staff members could give what } \\
\text { type of information }\end{array}$ & $4.19(0.86)$ & $3.67(1.07)$ & $0.00 *$ & 0.52 \\
\hline To feel it is alright to cry & $4.21(0.74)$ & $3.73(0.89)$ & 0.00 & 0.47 \\
\hline $\begin{array}{l}\text { To receive information about the patient at least once a } \\
\text { day }\end{array}$ & $4.75(0.43)$ & $4.29(0.62)$ & $0.00 *$ & 0.46 \\
\hline To have explanation given those are understandable & $4.68(0.51)$ & $4.25(0.63)$ & $0.00^{*}$ & 0.43 \\
\hline $\begin{array}{l}\text { To be told about transfer plans while they are being } \\
\text { made }\end{array}$ & $4.74(0.45)$ & $4.32(0.54)$ & $0.00 *$ & 0.42 \\
\hline $\begin{array}{l}\text { To be assured that the best care possible is being given } \\
\text { to patient }\end{array}$ & $4.83(0.38)$ & $4.43(0.55)$ & $0.00 *$ & 0.40 \\
\hline To have someone help with financial problem & $3.87(1.00)$ & $3.47(0.89)$ & $0.02 *$ & 0.40 \\
\hline To have directions as to what to do at the bedside & $4.60(0.53)$ & $4.24(0.58)$ & $0.00 *$ & 0.36 \\
\hline To have questions answered honestly & $4.87(0.39)$ & $4.5(0.55)$ & $0.00 *$ & 0.35 \\
\hline Being dealt with in cooperative and fair manner & $4.62(0.69)$ & $4.29(0.58)$ & $0.00 *$ & 0.33 \\
\hline To have visiting hours start on time & $4.47(0.64)$ & $4.15(0.80)$ & $0.02 *$ & 0.32 \\
\hline $\begin{array}{l}\text { Finding out about the possibilities for psychological } \\
\text { counseling }\end{array}$ & $4.26(0.81)$ & $3.96(0.52)$ & $0.02 *$ & 0.30 \\
\hline To talk about feelings about what has happened & $4.40(0.66)$ & $4.13(0.72)$ & $0.03 *$ & 0.27 \\
\hline To talk to the doctor every day & $4.66(0.59)$ & $4.44(0.68)$ & $0.05^{*}$ & 0.22 \\
\hline To have comfortable furniture in the waiting room & $4.23(0.72)$ & $4.03(0.80)$ & 0.14 & 0.20 \\
\hline To have good food available at hospital & $4.26(0.88)$ & $4.08(1.14)$ & 0.31 & 0.19 \\
\hline To know why things were done for the patient & $4.51(0.58)$ & $4.34(0.48)$ & 0.08 & 0.17 \\
\hline To know exactly what is being done for the patient & $4.53(0.72)$ & $4.37(0.54)$ & 0.17 & 0.16 \\
\hline To have the toilet near the waiting room & $4.30(0.82)$ & $4.20(0.67)$ & 0.47 & 0.10 \\
\hline To know the expected outcome & $4.77(0.51)$ & $4.72(0.48)$ & 0.55 & 0.05 \\
\hline $\begin{array}{l}\text { To have explanations of the environment before going } \\
\text { into the critical care unit first time }\end{array}$ & $4.43(0.69)$ & $4.49(0.50)$ & 0.59 & 0.06 \\
\hline
\end{tabular}

Abbreviations: FM, family members; HCWs: healthcare workers.

${ }^{1}$ Data are presented as mean (standard) deviation unless otherwise specified.

\section{References}

[1]. Saudi Gazette. Dr. Kurashi, N. (Thursday, 26 May 2011 - 23 Jumada Al-Akhir 1432 H). The regional president of WONCA. Kingdom-wide patient-Centered health care units proposed. Dammam, Saudi Arabia

[2]. Garrouste-Orgeas, M., Willems, V., Timsit, F., Diaw, F., Brochon, S., Vesin, A., Philippart, F., Tabah, A., Coque, I., Bruel, C., Moulard, M., Carlet, J \&Misset, J. (2010). Opinions of Families, Staff, and Patients about Family Participation in care in intensive care units. Journal of Critical Care. France. 25, 634-640.

[3]. Engströma, B., Uusitaloa.,\&Engströmb, A. (2011). Relatives' involvement in nursing care: A qualitative study describing critical care nurses' experiences. Intensive and Critical Care Nursing, 27, 1—9, Retrieved from; www.elsevier.com/locate/jaging

[4]. Bloomer, M., Morphet, J. O’Connor, M., Theol, B., Lee, S., Bioeth, B., Griffiths, D., Barrister \& Solicitor. (2013). Nursing care of the family before and after a death in the ICU—an exploratory pilot study. Australian Critical Care 26. 23- 28 Sweden.

[5]. Kinrade, T., Jackson, A., Tomnay, A. (n.d). The psychosocial needs of families during critical Illness: comparison of nurses' and family members' perspective. Australian Journal of Advance Nursing Volume 27, P 84-86. Australia Retrieved from; www.elsevier.com/locate/jaging

[6]. Khalaila, R. (2013) Patients' family satisfaction with needs met at the medical intensive care unit. Journal of Advanced Nursing. 69(5), 1172-1182.

[7]. Omari, F. (Sep 5, 2008). Perceived and Unmet Needs of Adult Jordanian Family Members of patients in ICU's. Clinical Scholarship. Journal of Nursing Scholar ship, Retrieved from: http://sfxhosted.exlibirisgroup.com/waldenu

[8]. Whitaker, A. (December 2008). Family Involvement in the Institutional Eldercare Context. Towards a new understanding. Journal homepage: Journal of Aging Studies. Retrieved from; www.elsevier.com/locate/jaging.

[9]. Pinkert, C., Holtgräwe, M., \&Remmers, H. (2013). Needs of relatives of breast cancer patients-The perspectives of families and nurses. Eur J OncolNurs. 17, 81-87.

[10]. Eberl, I., \&Schnepp W. (2008). Abschlussbericht. Die multizentrische Pilot studie der Family Health Nurse. EineUntersuchungüber die Machbarkeit der Familiengesundheitspflege in Deutschland.Universität Witten/Herdecke.

[11]. Jefford, M., Black, C., Grogan, S., Yeoman, G., White, V., \&Akkerman, D. (2005). Information and support needs of callers to the cancer helpline, the cancer council Victoria. European Journal of Cancer Care. 14, 113e123.

[12]. Tunin, R., Uziely, B., Woloski-Wruble, A.C.(2010). First degree relatives of women with breast cancer: who's providing information and support and who'd they prefer. Psycho-Oncology .19, 423e430.

[13]. Verhaeghe, S., Defloor, T., Van Zuuren, F., Duijnstee, M.S., \&Grypdonck, M. (2005)The needs and experiences of family members of adult patients in an intensive care unit: a review of the literature. Journal of Clinical Nursing. 14, 501-509.

[14]. Hinkle J.L. \& Fitzpatrick E. (2011). Needs of American relatives of intensives of intensive care patients: perceptions of relatives, physicians and nurses. Intensive and Critical Care Nursing. 27, 218-225.

[15]. Al-Mutair, A.S., Plummer, V., Clerehan, R., \&O’Brien, A.T. (2014). Families' needs of critical care Muslim patients in Saudi Arabia: a quantitative study.NursCrit Care. NursCrit Care. 19(4), 185-95. 
Table 1. Five Areas of the Critical Care Family Needs Inventory, Means and Standard Deviations for Families and Healthcare Workers

\begin{tabular}{|l|l|l|l|l|l|l|}
\hline & \multicolumn{4}{|l}{ Healthcare workers } & \multicolumn{1}{|c|}{ Family Members } \\
\hline & \multicolumn{1}{|c|}{ Areas } & Mean & SD & Areas & Mean & SD \\
\hline 1st & Assurance & 4.31 & 0.36 & Assurance & 4.77 & 0.31 \\
\hline 2nd & Comfort & 4.05 & 0.52 & Information & 4.54 & 0.40 \\
\hline 3rd & Information & 4.03 & 0.44 & Proximity & 4.46 & 0.41 \\
\hline 4th & Support & 3.59 & 0.45 & Comfort & 4.35 & 0.52 \\
\hline 5th & Proximity & 3.39 & 0.58 & Support & 4.29 & 0.44 \\
\hline
\end{tabular}

Table 2.Five Most Important Critical Care Family Needs Inventory Items as identified by Family Members and

\begin{tabular}{|l|l|l|}
\hline \multicolumn{2}{|l}{ Healthcare workers } & Family Members \\
\hline 1 & A-To know the expected outcome & To have questions answered honestly \\
\hline 2 & A-To have questions answered honestly & To be called at home about changes in the patient's condition \\
\hline 3 & $\begin{array}{l}\text { S-To have explanations of the environment before } \\
\text { going into the critical care unit first time }\end{array}$ & To be assured that the best care possible is being given to patient \\
\hline 4 & I-To talk to the doctor every day & To be told the truth even if is distressing \\
\hline 5 & $\begin{array}{l}\text { A-To be assured that the best care possible is being } \\
\text { given to patient }\end{array}$ & To know the specific facts about the patient \\
\hline
\end{tabular}

Table 3.Five Least Important Critical Care Family Needs Inventory Items as Identified by Healthcare Workers and Family Members

\begin{tabular}{|c|l|l|}
\hline & Healthcare workers & Family Members \\
\hline 1 & To have friends nearby for support & To have place to be alone while in the hospital \\
\hline 2 & $\begin{array}{l}\text { Talking about negative feeling such as rage and } \\
\text { guilt }\end{array}$ & To have friends nearby for support \\
\hline 3 & To be alone at any time & Talking about negative feeling such as rage and guilt \\
\hline 4 & To see the patient frequently & To have someone help with financial problem \\
\hline 5 & To visit at any time & To visit at any time \\
\hline
\end{tabular}

Table 4. Similarities between Healthcare Workers and Family Members'Perceived Needs

\begin{tabular}{|l|l|}
\hline \multicolumn{2}{|l|}{ Healthcare Workers and Family Members } \\
\hline 1 & A-to know the expected outcome \\
\hline 2 & A-to have questions answered honestly \\
\hline 3 & A-to be assured that the best care possible is being given to patient \\
\hline 4 & P-to be told about transfer plans while they are being made \\
\hline 5 & P-to receive information about the patient at least once a day \\
\hline
\end{tabular}

Table 5.Descriptive Statistics for Family Needs in Subscales (N=44 Items) ${ }^{1}$

\begin{tabular}{|c|c|c|c|c|}
\hline Group Statistics & $\begin{array}{l}\text { FMs } \\
(\mathrm{n}=53)\end{array}$ & $\begin{array}{l}\text { HCWs } \\
(\mathrm{n}=79)\end{array}$ & $\mathrm{P}$-value & $\begin{array}{l}\text { Mean } \\
\text { Difference }\end{array}$ \\
\hline To visit at any time & $3.70(1.35)$ & $1.49(0.92)$ & $0.00 *$ & 2.20 \\
\hline To see the patient frequently & $4.60(0.60)$ & $2.63(1.46)$ & $0.00^{*}$ & 1.97 \\
\hline To be alone at any time & $4.32(0.87)$ & $2.72(1.15)$ & $0.00 *$ & 1.60 \\
\hline $\begin{array}{l}\text { To be called at home about changes in the patient's } \\
\text { condition }\end{array}$ & $4.83(0.38)$ & $3.59(1.04)$ & $0.00^{*}$ & 1.24 \\
\hline $\begin{array}{l}\text { To have another person with you when visiting the } \\
\text { critical care unit }\end{array}$ & $4.42(0.75)$ & $3.28(0.95)$ & $0.00^{*}$ & 1.14 \\
\hline Talking about negative feeling such as rage and guilt & $4.00(0.88)$ & $2.87(1.28)$ & $0.00 *$ & 1.13 \\
\hline To have visiting hours changed for specific conditions & $4.26(0.96)$ & $3.16(1.27)$ & 0.00 & 1.10 \\
\hline To have friends nearby for support & $4.13(0.68)$ & $3.09(1.15)$ & $0.00 *$ & 1.04 \\
\hline To talk about the possibility of patients death & $4.34(0.90)$ & $3.34(1.29)$ & $0.00 *$ & 1.00 \\
\hline To have place to be alone while in the hospital & $4.19(0.96)$ & $3.20(1.16)$ & $0.00 *$ & 0.99 \\
\hline To have the waiting room near the patient & $4.36(0.71)$ & $3.46(1.12)$ & $0.00^{*}$ & 0.90 \\
\hline To help with the patient physical care & $4.66(0.52)$ & $3.86(0.98)$ & $0.00 *$ & 0.80 \\
\hline To be told the truth even if is distressing & $4.79(0.45)$ & $4.03(0.73)$ & $0.00 *$ & 0.77 \\
\hline $\begin{array}{l}\text { To know about the types of staff members talking care } \\
\text { of the patient }\end{array}$ & $4.58(0.54)$ & $3.82(1.02)$ & $0.00 *$ & 0.76 \\
\hline To feel there is hope & $4.72(0.50)$ & $3.97(0.78)$ & $0.00^{*}$ & 0.74 \\
\hline To know the specific facts about the patient & $4.79(0.45)$ & $4.09(0.56)$ & $0.00 *$ & 0.70 \\
\hline To have a telephone near the waiting room & $4.32(0.89)$ & $3.65(1.08)$ & $0.00^{*}$ & 0.68 \\
\hline To be encouraged to express emotions & $4.38(0.77)$ & $3.75(0.76)$ & $0.00 *$ & 0.63 \\
\hline To be told about pastoral services & $4.40(0.60)$ & $3.78(0.78)$ & $0.00 *$ & 0.61 \\
\hline To have someone be concerned with your heath & $4.55(0.61)$ & $3.94(0.74)$ & $0.00^{*}$ & 0.61 \\
\hline To feel that the hospital personal care about the patient & $4.74(0.45)$ & $4.16(0.61)$ & $0.00 *$ & 0.57 \\
\hline $\begin{array}{l}\text { To have the specific person to call at the hospital when } \\
\text { unable to visit }\end{array}$ & $4.34(0.88)$ & $3.78(1.00)$ & 0.00 & 0.56 \\
\hline
\end{tabular}




\begin{tabular}{|c|c|c|c|c|}
\hline To know how the patient is being treated medically & $4.72(0.57)$ & $4.18(0.59)$ & $0.00 *$ & 0.54 \\
\hline $\begin{array}{l}\text { To know which type of staff members could give what } \\
\text { type of information }\end{array}$ & $4.19(0.86)$ & $3.67(1.07)$ & $0.00 *$ & 0.52 \\
\hline To feel it is alright to cry & $4.21(0.74)$ & $3.73(0.89)$ & 0.00 & 0.47 \\
\hline $\begin{array}{l}\text { To receive information about the patient at least once a } \\
\text { day }\end{array}$ & $4.75(0.43)$ & $4.29(0.62)$ & $0.00 *$ & 0.46 \\
\hline To have explanation given those are understandable & $4.68(0.51)$ & $4.25(0.63)$ & $0.00 *$ & 0.43 \\
\hline $\begin{array}{l}\text { To be told about transfer plans while they are being } \\
\text { made }\end{array}$ & $4.74(0.45)$ & $4.32(0.54)$ & $0.00 *$ & 0.42 \\
\hline $\begin{array}{l}\text { To be assured that the best care possible is being given } \\
\text { to patient }\end{array}$ & $4.83(0.38)$ & $4.43(0.55)$ & $0.00^{*}$ & 0.40 \\
\hline To have someone help with financial problem & $3.87(1.00)$ & $3.47(0.89)$ & $0.02 *$ & 0.40 \\
\hline To have directions as to what to do at the bedside & $4.60(0.53)$ & $4.24(0.58)$ & $0.00 *$ & 0.36 \\
\hline To have questions answered honestly & $4.87(0.39)$ & $4.5(0.55)$ & $0.00 *$ & 0.35 \\
\hline Being dealt with in cooperative and fair manner & $4.62(0.69)$ & $4.29(0.58)$ & $0.00 *$ & 0.33 \\
\hline To have visiting hours start on time & $4.47(0.64)$ & $4.15(0.80)$ & $0.02 *$ & 0.32 \\
\hline $\begin{array}{l}\text { Finding out about the possibilities for psychological } \\
\text { counseling }\end{array}$ & $4.26(0.81)$ & $3.96(0.52)$ & $0.02 *$ & 0.30 \\
\hline To talk about feelings about what has happened & $4.40(0.66)$ & $4.13(0.72)$ & $0.03 *$ & 0.27 \\
\hline To talk to the doctor every day & $4.66(0.59)$ & $4.44(0.68)$ & $0.05^{*}$ & 0.22 \\
\hline To have comfortable furniture in the waiting room & $4.23(0.72)$ & $4.03(0.80)$ & 0.14 & 0.20 \\
\hline To have good food available at hospital & $4.26(0.88)$ & $4.08(1.14)$ & 0.31 & 0.19 \\
\hline To know why things were done for the patient & $4.51(0.58)$ & $4.34(0.48)$ & 0.08 & 0.17 \\
\hline To know exactly what is being done for the patient & $4.53(0.72)$ & $4.37(0.54)$ & 0.17 & 0.16 \\
\hline To have the toilet near the waiting room & $4.30(0.82)$ & $4.20(0.67)$ & 0.47 & 0.10 \\
\hline To know the expected outcome & $4.77(0.51)$ & $4.72(0.48)$ & 0.55 & 0.05 \\
\hline $\begin{array}{l}\text { To have explanations of the environment before going } \\
\text { into the critical care unit first time }\end{array}$ & $4.43(0.69)$ & $4.49(0.50)$ & 0.59 & 0.06 \\
\hline
\end{tabular}

Abbreviations: FM, family members; HCWs: healthcare workers.

${ }^{1}$ Data are presented as mean (standard) deviation unless otherwise specified. 